\title{
Iron-Rich Foods Intakes among Urban Senegalese Adolescent Girls
}

\author{
Aminata Ndene Ndiaye ${ }^{1, *}$, Isabelle Galibois ${ }^{1}$ and Sonia Blaney ${ }^{2}$ \\ ${ }^{1}$ Laval University Quebec City, Quebec, G1V 0A6, Canada \\ ${ }^{2}$ Moncton University, Moncton, New Brunswick, E1A 3E9, Canada
}

\begin{abstract}
Intake of iron-rich foods was investigated in Senegalese adolescent girls. A cross-sectional survey was conducted among 136 girls aged 13 to 18, attending two colleges in Dakar. Data on the consumption of iron-rich foods over the previous week were collected through a food frequency questionnaire. Results show that $12 \%$ of the girls had consumed dishes made with iron-rich foods 3 times or less in the past seven days, 34\%, 4 to 6 times, and $54 \%, 7$ times and above. However, $83 \%$ of the girls had an intake of iron-rich foods below the $84 \mathrm{~g}$ per day recommended for animal protein sources by the EAT-Lancet Commission on Healthy Diets from Sustainable Food Systems. The diet of Senegalese adolescent girls seems conducive to iron deficiency. To define effective interventions to improve the situation, investigating underlying factors to the low consumption of iron-rich foods is warranted.
\end{abstract}

Keywords: Iron-rich foods, food intake, adolescent girls, Africa, food frequency questionnaire.

\section{INTRODUCTION}

Anaemia is a global public health problem affecting populations living in both developing and developed countries, with major consequences on human health as well as on social and economic development [1]. It occurs at all stages of the life cycle, but it is more prevalent in pregnant women, young children, and adolescent girls. In most populations, anaemia is primarily due to iron deficiency and is the late stage of a relatively long process of deterioration of iron stores [1]. Worldwide, around $40 \%$ of children less than five years of age and one-third of women of reproductive age (15-49 years) are anaemic [1,2]. According to Akseer et al. [3], iron deficiency anaemia (IDA) and iron deficiency are the leading causes of disability-adjusted life years lost by adolescent girls aged 10-19. During adolescence, good nutrition is critical to support rapid physical growth and development. Although the first 1 000 days of life are a priority for preventing malnutrition, adolescence provides a second window of opportunity for a high return on investments with nutritional interventions [4].

Despite the importance of having a healthy diet, often adolescents may have limited food options or be surrounded by poor nutrition choices (e.g., fast foods, sweets, sugary beverages), especially in urban areas [4]. It has been reported that the diet of adolescents living in low and middle-income countries (LMIC) is nutritionally poor [5], with limited diversity, mainly

*Address correspondence to this author at the Laval University Quebec City, Quebec, G1V 0A6, Canada; Tel: 14186562131 Ext: 402904; Fax: 1418656 3353; E-mail: aminata-ndene.ndiaye.1@ulaval.ca comprising plant-based food sources and with few fruits, vegetables and animal products [6]. Such a situation can favour IDA given that adolescents may not have access to iron-rich foods and thus, have an insufficient intake of iron that might, in addition, be poorly absorbed if their diets contain high levels of phytate or phenolic compounds. The situation is even more worrying for adolescent girls since they have higher iron requirements due to menstruation.

Of all countries, Senegal has been ranked among the top states with regards to the prevalence of anaemia among women of reproductive age [1]. The latest data show that $54 \%$ of women aged 15 to 49 are anaemic, and this rate is slightly higher $(57 \%)$ among adolescent girls (15-19 years) [7]. More worrisome is that the situation has not changed over the past decade as $56 \%$ of adolescent girls were reported to be anaemic in 2010-2011 [2].

To contribute to the prevention of iron deficiency among adolescent girls in Senegal, it is essential to understand their dietary behaviour to identify interventions that could help improve their access to and consumption of iron-rich foods. The objective of this research was to assess the consumption of ironrich foods among Senegalese urban adolescent girls.

\section{MATERIALS AND METHODS}

\section{Study Design and Sample}

This study was a cross-sectional survey targeting adolescent girls from two middle-schools in Dakar, Senegal. It was part of larger research aiming to assess individual and environmental determinants 
associated with iron-rich foods' daily consumption among adolescent girls (13 to 18 years old). After that, to define, test, and assess the impact of interventions to improve the iron-rich food consumption.

The two colleges were chosen purposively in Dakar. In each school, all classes attended by adolescent girls aged 13-18 years were selected and, in each class, all girls were invited to participate.

\section{Data Collection}

Prior to the data collection, 16 interviewers were recruited based on the following criteria: being a graduate student at the IPDSR (Institut de formation et de recherche en Population, Développement et Santé de la Reproduction of the Université Cheikh Anta Diop of Dakar) and having completed the data collection module of the Master programme, being fluent in Wolof (local language) and being available for the entire duration of the research. During a four-day period, all interviewers were trained by the first author on the methodology and tools for data collection.

Data collection was conducted in January and February 2019. Because the food frequency questionnaire (FFQ) is unique in its ability to examine specific nutrients, habitual intake and dietary behaviour [8], it was chosen to document the consumption of ironrich foods by adolescent girls. Indeed, the FFQ helps provide information on food consumption over a given time interval, thus capturing usual consumption. It also collects information on the size of portions of food consumed to calculate nutrient intakes [8-10].

An original FFQ was developed for this study. First, a food list was made based on the first author's (who is Senegalese) knowledge of foods and dishes available in the area, including those sold by street vendors near the schools. Foods targeted in the FFQ were single iron-rich foods from animal sources, namely red meat (beef, mutton, lamb), poultry, fish, shellfish, organ meats, and eggs according to the current list used in national surveys [7].

Before initiating the data collection, to ensure the clarity and completeness of the questionnaire, the FFQ was administered to a group of ten adolescent girls of one of the targeted colleges. No major modifications were made, so the final version of the FFQ was administered to each participating girl through an interview conducted in a quiet area of her school.

The FFQ allowed documenting each girl's frequency of consumption of dishes containing iron-rich foods in the seven days preceding the survey, as well as the average amount of iron-rich food contained in each dish consumed. As such, for each iron-rich food, it was asked whether it had been consumed in different forms or dishes such as fried, grilled, or in a sandwich, or combined with rice, pasta or any other foods. If so, the frequency of consumption in the past seven days was recorded, and the iron-rich food quantity per intake was determined as follows. For dishes that were not purchased (e.g. those consumed or prepared at home), the interviewer used plastic food models, actual foods, and local utensils (e.g. cup, bowl, plate, spoon) to help the girl accurately estimate the amounts in grams of iron-rich foods consumed per intake. For dishes that were purchased by the girl from street vendors near the colleges, samples were bought, and their iron-rich ingredients were weighted beforehand by the research team. Prices were also collected to help at quantifying the consumption of iron-rich foods. Hence, the consumption by the girls of these iron-rich foods was recorded based on the prices they paid; for example, in a beef meat sandwich costing 200 FCFA. ${ }^{1}$, the average quantity of beef meat was $38 \mathrm{~g}$. So, when a girl reported having consumed this sandwich (a 200 FCFA beef meat sandwich), the price was registered on the FFQ for the sole purpose of assessing the quantity of beef meat it represented.

Data on household socioeconomic characteristics were collected through an interview of approximately 45-60 minutes conducted at home with the head of the household of each participating adolescent girl, using the standardized and validated questionnaire of the Senegalese Demographic and Health Surveys [7]. Information on the composition of the household, such as the age and gender of each member, as well as their level of education, was collected.

\section{Data Analysis}

FFQ data were entered directly into SPSS (Statistical Package for Social Sciences (SPSS), Version 21.0, Armonk, NY, IBM Corporation). Mean numbers of intakes over the past seven days were calculated for each dish. Proportions of girls who had consumed each dish were also computed. The participants' distributions according to their frequency of consumption over seven days of all dishes containing iron-rich foods, dishes containing poultry,

\footnotetext{
${ }^{1}$ Francs of the Communauté Financière Africaine.
} 
meat and fish combined, and dishes containing eggs were also established.

For each girl and each dish containing iron-rich food, the average amount per intake of iron-rich food was multiplied by the number of intakes in the past seven days. The total amount in grams of every single iron-rich food consumed over the seven days was calculated and then reported daily.

The daily intake $(\mathrm{g})$ of all iron-rich foods combined (red meat/poultry/fish/offal and eggs) was also calculated. These daily intakes were compared to the amounts recommended for animal protein sources in the EAT-Lancet Commission document "Healthy Diet from Sustainable food systems" [11]. Proportions of girls below and above the recommended daily amounts of animal protein sources included in the healthy diet were calculated.

\section{Ethics}

The study has been approved by the ethical committee of the National Health Research of Senegal 000106 / MSAS / DPRS / CNERS and by the Research Ethics Committee of Laval University 2018-214 / 17-122018. Authorizations were also obtained from the Ministry of the National Education / School Medical Control Division, Dakar / Senegal. Written informed consent was obtained from the parent/tutor of each adolescent at the beginning of the study, and each girl also provided her written consent to participate.

\section{RESULTS}

The mean age of adolescents who participated in this study was 15 years (Table 1). Around $60 \%$ of them were living in male-headed households. The mean age of the head of the household was about 50 years (Table 1).

Regarding the frequency of consumption of dishes made with iron-rich foods, fish with rice was consumed by almost nine out of ten girls and among those, four times on average over the past seven days (Table 2). The meat was consumed in a sandwich or with rice by around one-third of adolescents on average twice in the past seven days, while egg sandwiches were eaten by three-quarters of girls, on average between once and twice during the same period. Poultry was eaten by a third of adolescent girls either as a part of an onion sauce or with rice, twice in the past seven days on average. The liver was eaten in a sandwich by about $2 \%$ of adolescents on average once in the past seven days. In total, virtually all adolescent girls (99\%) consumed a dish that contained iron-rich foods at least once in the past seven days. The overall average number of intakes in the past seven days was 6.8 (Table 2). Moreover, $54 \%$ of girls had consumed ironrich food dishes 7 times or more in the past seven days, $34 \%$ between 4 and 6 times and 12\%, 3 times or less (Figure 1).

Table 1: Characteristics of Adolescents and their Households ( $\mathbf{N}=136)$

\begin{tabular}{|l|c|c|}
\hline Characteristics & Mean I SD & $\%$ \\
\hline \hline Adolescent & $15.0 \pm 1.2$ & \\
Age (years) & & 59 \\
\hline Household (HH) & & \\
\hline - Gender of the head (male) & & 45 \\
\hline - Education level of head of HH: & 19 \\
- None & & 8 \\
- Primary incomplete / complete & 2 \\
- Secondary incomplete / complete & & \\
- Superior / University & & \\
- Other / Not Applicable & $53.1 \pm 13.6$ & \\
\hline - Age of head of HH (years) & $8 \pm 4$ & \\
\hline - Number of persons in the HH & & \\
\hline
\end{tabular}

When considering the frequency of consumption of iron-rich foods by sub-group, $35 \%$ consumed foods from the red meat/poultry/fish dishes combined at least 7 times in the past seven days, $24 \%$, between 4 and 6 times and $41 \%, 3$ times and less (Figure 2). Regarding eggs, none of the girls consumed eggs dishes 7 or more times in the past seven days, $6 \%$ between 4 and 6 times, $32 \% 2$ or 3 times, and around two thirds $(61 \%), 0$ or 1 time (Figure 3 ).

In terms of quantities, $30 \%$ of girls consumed more than $170 \mathrm{~g}$ of fish in the past seven days, while $75 \%$ ate more than $85 \mathrm{~g}$. In contrast, 30\%, 37\% and $39 \%$ ate more than $85 \mathrm{~g}$ of meat, chicken and eggs, respectively, during the same period (Table 3 ). The average daily consumption of all iron-rich foods over the past seven days was estimated at $58 \pm 33 \mathrm{~g}$ per day, which comprises $29 \mathrm{~g}$ of fish, $8 \mathrm{~g}$ of meat, $10 \mathrm{~g}$ of chicken, $10 \mathrm{~g}$ of egg, $0.4 \mathrm{~g}$ of the liver and $0.1 \mathrm{~g}$ of shellfish (results not shown).

Overall, $83 \%$ of the girls had an estimated intake of iron-rich foods below the $84 \mathrm{~g}$ per day recommended for animal protein sources by the EAT-Lancet Commission on Healthy Diets from Sustainable Food Systems (Figure 4). 
Table 2: Frequency of Consumption of Dishes that Contain Iron-Rich Foods in the Past Seven Days among Adolescent Girls ( $\mathbf{N}=136)$

\begin{tabular}{|c|c|c|}
\hline Dish & $\begin{array}{c}\text { Mean } \pm \text { SD number of intakes } \\
\text { (past } 7 \text { days) * }\end{array}$ & $\begin{array}{l}\% \text { of girls who consumed the dish } \\
\text { (past } 7 \text { days) ** }\end{array}$ \\
\hline \multicolumn{3}{|c|}{ Fish dishes } \\
\hline Rice and fish & $4.0 \pm 1.9$ & 86 \\
\hline Fish sandwich & $1.3 \pm 0.6$ & 2 \\
\hline Fish with Yassa sauce & $1.3 \pm 0.5$ & 4 \\
\hline \multicolumn{3}{|c|}{ Red meat dishes (beef, mutton, lamb) } \\
\hline Rice and meat & $1.9 \pm 1.1$ & 35 \\
\hline Meat sandwich & $2.4 \pm 1.5$ & 37 \\
\hline Meat with Yassa sauce & $1.5 \pm 0.7$ & 1 \\
\hline Meat with peanut sauce & $1.0 \pm 0.0$ & 1 \\
\hline Vermicelli with meat & $1.0 \pm 0.0$ & 1 \\
\hline Couscous with meat & $1.0 \pm 0.0$ & 1 \\
\hline \multicolumn{3}{|c|}{ Egg dish } \\
\hline Scrambled eggs sandwich & $1.4 \pm 1.2$ & 75 \\
\hline \multicolumn{3}{|c|}{ Chicken dishes } \\
\hline Rice and chicken & $1.6 \pm 1.2$ & 26 \\
\hline Chicken sandwich & $1.5 \pm 0.7$ & 32 \\
\hline Chicken with Yassa sauce & $2.0 \pm 1.4$ & 1 \\
\hline Vermicelli with chicken & $1.3 \pm 0.6$ & 2 \\
\hline \multicolumn{3}{|c|}{ Liver dish } \\
\hline Liver sandwich & $1.3 \pm 0.6$ & 2 \\
\hline \multicolumn{3}{|c|}{ Shellfish dish } \\
\hline Shrimp sauce & $1.0 \pm 0.0$ & 2 \\
\hline Overall & $6.8 \pm 2.9^{* * *}$ & 99 \\
\hline
\end{tabular}

*Among girls who consumed the dish.

$\star * \%$ of girls who consumed the dish at least once in the past seven days.

${ }^{* * *}$ Average total number of intakes of dishes that contain iron-rich foods in the past seven days.

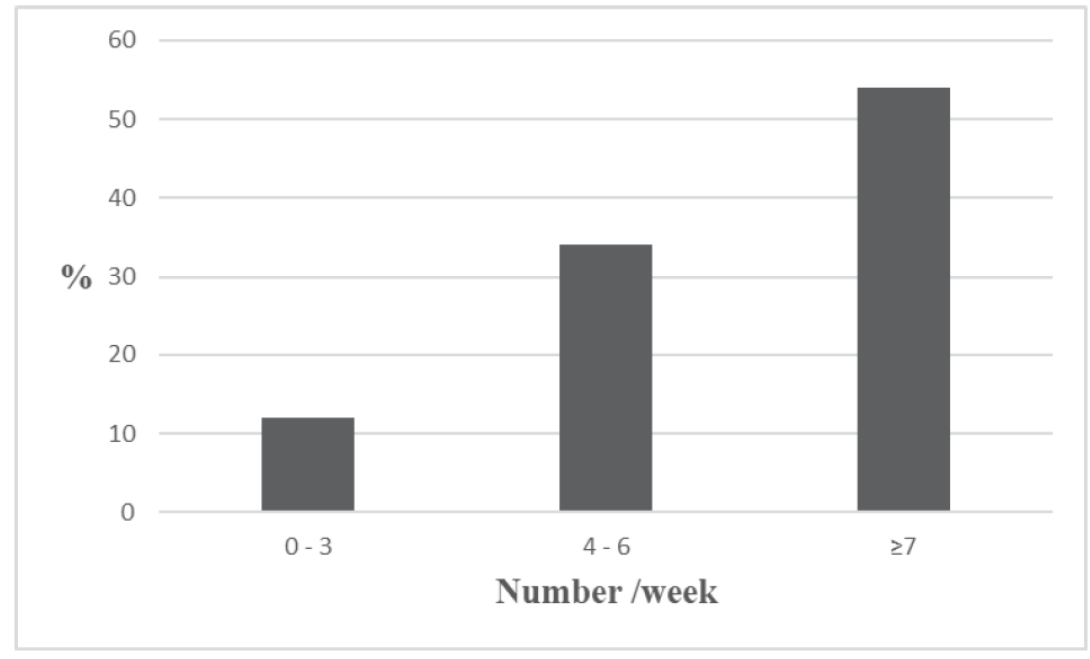

Figure 1: Proportions (\%) of girls by the frequency of consumption of all iron-rich foods (IRF) combined in the past seven days $(\mathrm{N}=136)$. 


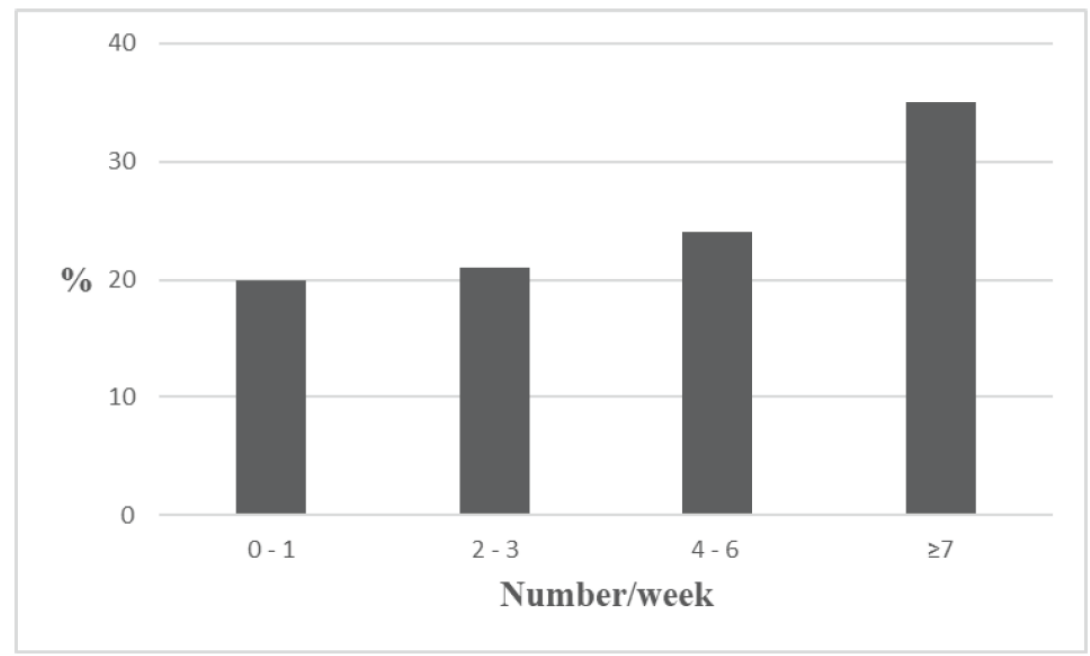

Figure 2: Proportions (\%) of girls by frequency of consumption of meat/poultry/fish in the past seven days ( $\mathrm{N}=136)$.

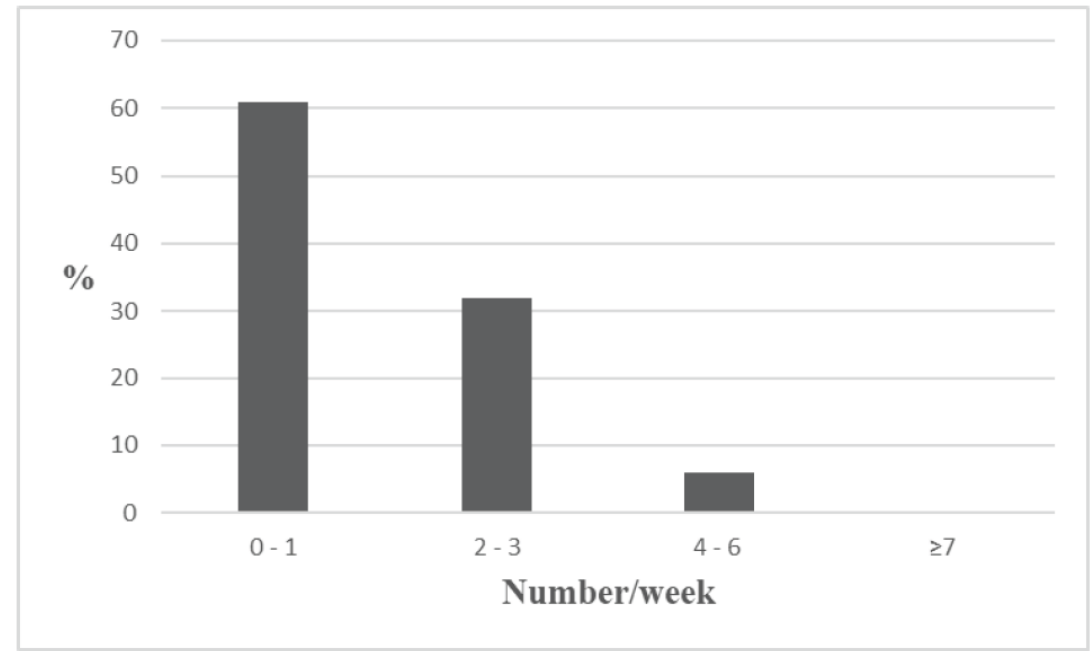

Figure 3: Proportions (\%) of girls by frequency of consumption of eggs in the past seven days $(\mathrm{N}=136)$.

Table 3: Distribution (\%) of Adolescent Girls According to the Total Quantity (g) of each Iron-Rich Food Consumed in the Past Seven Days $(\mathrm{N}=136)$

\begin{tabular}{|c|c|c|c|c|c|}
\hline \multirow{2}{*}{ Iron-rich foods } & \multicolumn{5}{|c|}{$\%$ of participants } \\
\hline & $0 \mathrm{~g}$ & $1-84 \mathrm{~g}$ & $85-169 \mathrm{~g}$ & $170-254 \mathrm{~g}$ & $\geq 255 \mathrm{~g}$ \\
\hline Fish & 9 & 15 & 24 & 21 & 30 \\
\hline Meat & 54 & 15 & 15 & 7 & 8 \\
\hline Chicken & 41 & 20 & 22 & 10 & 5 \\
\hline Shellfish & 98 & 2 & 0 & 0 & 0 \\
\hline
\end{tabular}

\section{DISCUSSION}

The main objective of this research was to assess the consumption of iron-rich foods among a group of adolescent girls attending two colleges in the city of
Dakar, Senegal. A food frequency questionnaire was developed and used to have an optimal overview of the diversity of consumption of iron-rich foods in their different forms and dishes. 


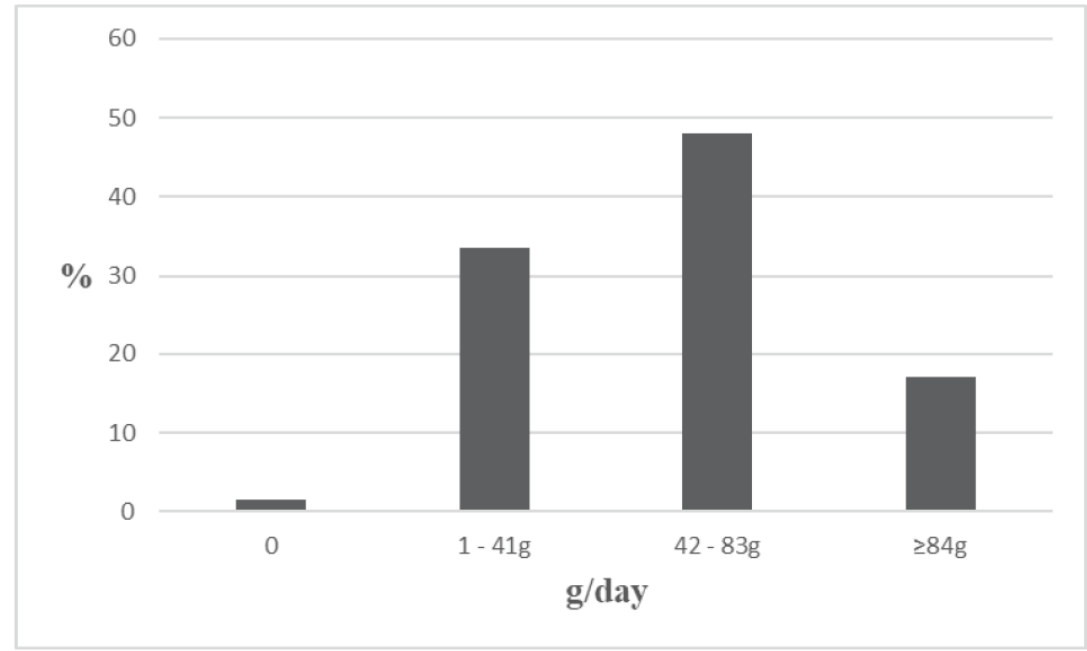

Figure 4: Proportions (\%) of girls by average daily consumption (g/day) of all iron-rich foods combined $(N=136)$.

On average, $58 \mathrm{~g}$ of iron-rich foods were consumed per day. Fish was the iron-rich food most commonly consumed by almost nine out of ten adolescent girls, followed by eggs, consumed by about seven out of ten. Moreover, our results show that respectively about $40 \%$ and $55 \%$ of adolescent girls did not consume any poultry and meat during the seven-day period.

Overall, in our study, the proportion of girls who consumed meat/poultry/fish 4 times or more per week was larger $(59 \%)$ than the proportion $(46 \%)$ reported in the systematic review of the literature by Keats et al. [5] which included ten studies investigating the intake of various food groups among adolescent girls in subSaharan Africa. In addition, the results of Keats et al. [5] showed that just over half (54\%) of girls aged 10-19 years consumed meat, poultry, and fish 3 times or less per week, whereas, in our context, this proportion was lesser $(41 \%)$. They did not specify the weekly frequencies of egg consumption but reported that overall, $54 \%$ of adolescent girls consumed eggs [5], a percentage lower than that of our study $(75 \%)$. Of the aforementioned ten studies, only six $(n=4,215$ participants) reported different weekly frequencies of consumption, using data obtained from the FFQ in most cases. None of these studies was conducted in the West African region. The discrepancy between our results and those of [5] may be attributed to differences in the age of adolescents (14 - 18 in our study vs 10 19 years in theirs) but also to differences between Senegal adolescent eating habits and those from countries located in the South (e.g. South Africa and Mozambique), Central (e.g. Nigeria) or the Eastern part (e.g. Ethiopia, Sudan) of the African continent.

In this study, in addition to the frequency of consumption of iron-rich foods, quantities per intake were also evaluated. A study by Tayel and Ezzat [12] carried out in Alexandria, Egypt, among adolescents aged 11 to 16 years indicated a daily consumption of $96 \pm 4 \mathrm{~g}$ of meat and meat products (red meat, chicken and organ meats), $41 \pm 5 \mathrm{~g}$ of fish and $45 \pm 4 \mathrm{~g}$ of eggs, which are all above estimated mean daily quantities reported in our study of $19 \pm 21 \mathrm{~g}, 29 \pm 22 \mathrm{~g}$, and $10 \pm 9 \mathrm{~g}$ respectively for the same types of ironrich foods. In addition, anaemia was significantly associated with a low intake of iron-rich foods [12]. This confirmed that the limited amount of iron-rich foods consumed is linked to a low iron intake, one of the main causes of iron deficiency and iron-deficiency anaemia [13].

Even though in the present study the consumption of iron-rich foods by girls appears to be quite acceptable in terms of weekly frequency, the average amount consumed per day was low and well below the average amount per day recommended for animal protein sources by the EAT-Lancet Commission on Healthy Diets from Sustainable Food Systems $(58 \mathrm{~g} /$ day vs $84 \mathrm{~g} /$ day).

Knowing that $100 \mathrm{~g}$ of beef contains on average 2.0 $\mathrm{mg}$ of iron, while fish and poultry have about $1.0 \mathrm{mg}$, and eggs, $1.4 \mathrm{mg}$ [14], $58 \mathrm{~g}$ of iron-rich foods per day, does not provide a large quantity of iron, especially when fish is the most common food consumed as it was the case in our context.

From the data from this study, it can be extrapolated that if each girl's average daily intake of iron-rich foods could be increased by $27 \mathrm{~g}$, such an addition would increase the average daily intake of iron-rich foods to $85 \mathrm{~g}$. Consequently, the proportion of girls below the 
amount recommended in the EAT-Lancet reference diet for animal protein sources would be reduced from $83 \%$ to $52 \%$. In other words, with such an increase, around half of the girls would have an iron-rich dietary intake greater than or equal to the $84 \mathrm{~g}$ per day recommended for animal protein sources by the EATLancet Commission on Healthy Diets from Sustainable Food Systems. Hence, efforts to encourage the consumption of larger portions of iron-rich foods in adolescent girls would likely help many of them to increase the likelihood of meeting their iron requirements.

In summary, in our context, while the frequency of consumption of dishes containing some iron-rich foods seems rather acceptable, there is no doubt that the amounts of iron-rich foods should be increased for all girls at least up to the daily levels suggested by the healthy diet from sustainable food systems. With that in mind, moving on with dietary approaches, specifically with modifications of adolescent girls' diet, could be a way to improve their consumption of iron-rich foods leading to an increase in iron intake and, consequently, to a potential reduction of iron deficiency anaemia among this group [4]. However, it is recognized that adolescent girls face significant obstacles in improving their diet, including the cost and access to healthy foods and the fact that they may have a limited understanding of the nutritional qualities of foods [4]. Whatever factors underlie the limited consumption of iron-rich foods among adolescent girls, to be effective, interventions aiming at increasing the consumption of these foods should be grounded in a sound assessment and analysis of these factors and, as such, the use of psychosocial theories could be helpful to guide the process. Hence, documenting individual and environmental factors associated with the consumption of iron-rich foods in adolescent girls could be the next step to design and implement an effective programme aiming at increasing their intake.

Our study has many strengths that should be highlighted. To our knowledge, this is the first research in Senegal that evaluates comprehensively the consumption of iron-rich foods among adolescent girls, including frequency of intake and quantity per intake. Another strength is developing an FFQ that specifically aims to assess the consumption of iron-rich foods in adolescent girls. Although this FFQ certainly deserves to be validated, it is a significant attempt to develop a tool that could be used to gather data on the consumption of iron-rich foods among this group. However, our study has also some limitations that must be recognized. First, the sample was purposive and, consequently, results cannot be generalized to the entire population of adolescent girls. Secondly, data on food intake were collected during the school period. Although it represents the major part of the year, it is possible that during this period, where most of the day was spent at school, the food intake of adolescents was different from what it would be during vacation. The data collection was also conducted over two months, thus not reflecting the impact of seasonality on food intakes. Also, since girls were self-reporting their food intake, it is possible that there was either underreporting or misreporting [6]. To help at overcoming this potential bias that may have affected the reliability of our data, plastic food models, real foods, food prices and local utensils were used to determine food quantities.

In conclusion, the intake of iron-rich foods was quantitatively too low among our group of urban Senegalese adolescent girls. This situation may contribute to the acceleration of the double burden of malnutrition among this age group as well as later on when they will be adults. There is no doubt that the amounts of iron-rich foods in their diet should be increased, and to do so, individual and environmental factors influencing intake should be investigated to help to determine what to do and how to do it.

\section{ACKNOWLEDGEMENTS}

We would like to thank all adolescent girls for their participation in this study. We are also grateful to the survey team, the directors of the two colleges as well as the representative of the Ministry of Education of the Dakar Region, Senegal, for their continuous and significant support. We would like to thank $\mathrm{Pr}$ Mohamadou Sall, Director of the IPDSR at the University Cheikh Anta Diop and $\mathrm{Dr}$ Aliou Abdourahmane Dia, Head of the School Medical Control Division, for their outstanding support and contribution to the implementation of this research. We also thank Ms Madélie Giguère-Johnson from the University de Moncton for her support in the data collection and entry. The financial support of the Queen Elizabeth scholarship programme funded by the International Development Research Center and the Social Sciences and Humanities Research Council of Canada is acknowledged.

\section{REFERENCES}

[1] WHO. Nutritional anaemias: tools for effective prevention and control 2017. Available from: https://www.who.int/ publications/i/item/9789241513067 
[2] ANSD, ICF. Enquête Démographique et de Santé à Indicateurs Multiples au Sénégal (EDS-MICS) 2010-2011. Calverton, Maryland, USA: ANSD et ICF International 2012.

[3] Akseer N, Al-Gashm S, Mehta S, Mokdad A, Bhutta ZA. Global and regional trends in the nutritional status of young people: a critical and neglected age group 2017. https://doi.org/10.1111/nyas.13336

[4] UNICEF. Children, food and nutrition: Growing well in a changing world 2019. Available from: https://nutritionconnect. org/resource-center/sowc-2019-children-food-and-nutritiongrowing-well-changing-world

[5] Keats EC, Aviva Rappaport, Reena Jain, Christina Oh, Shailja Shah, Zulfiqar A. Bhutta. Diet and Eating Practices among Adolescent Girls in Low- and Middle-Income Countries: A Systemic Review. Arlington, VA: Strengthening Partnerships, Results, and Innovations in Nutrition Globally (SPRING) project. 2018. https://doi.org/10.3390/nu10121978

[6] Ochola S, Masibo PK. Dietary Intake of Schoolchildren and Adolescents in Developing Countries. Ann Nutr Metab 2014; 64: $24-40$.

https://doi.org/10.1159/000365125

[7] Agence Nationale de la Statistique et de la Démographie (ANSD) [Sénégal], et ICF. Sénégal: Enquête Démographique et de Santé Continue (EDS-Continue 2017). Rockville, Maryland, USA: ANSD et ICF.2018
[8]

Health Canada. Canadian Nutrient File, Health Canada,
Ottawa, Canada. Available online: https://food-
nutrition.canada.ca/cnf-fce/index-eng.jsp (accessed on 26 May 2020).

https://doi.org/10.6000/1929-4247.2021.10.01.1

(C) 2021 Ndiaye et al.; Licensee Lifescience Global.

This is an open access article licensed under the terms of the Creative Commons Attribution Non-Commercial License (http://creativecommons.org/licenses/by-nc/3.0/) which permits unrestricted, non-commercial use, distribution and reproduction in any medium, provided the work is properly cited. 